\title{
Development and Validation of Content Uniformity Analytical Procedure of Glipizide Extended Release Tablet
}

\author{
Ilma Nugrahani ${ }^{*}$ Indhah Fatmawati, Slamet Ibrahim \\ Pharmacochemistry Research Group, School of Pharmacy, Bandung Institute of Technology, Jalan Ganesha No. 10, Bandung 40132, Indonesia.
}

\begin{tabular}{l} 
ARTICLE INFO \\
\hline Article history: \\
Received on: $16 / 06 / 2016$ \\
Revised on: 16/08/2016 \\
Accepted on: 20/09/2016 \\
Available online: $28 / 12 / 2016$ \\
\hline Key words: \\
Glipizide, Extended Release \\
Tablet, Solid Phase \\
Extraction, High \\
Performance Liquid \\
Chromatography (HPLC), \\
Validation.
\end{tabular}

ARICLE INFO

Article history:

Received on: 16/06/2016

Accepted on: 20/09/2016

Validation.

\begin{abstract}
Glipizide is an oral anti-diabetic drug which belongs to the class of second-generation sulfonyl-ureas. The matrices of an extended release (ER) dosage form often bring some problems in the analytical work, so it needs suitable procedure for extraction and separation. In this experiment, the glipizide ERs were prepared for a quantitative analysis by solid phase extraction (SPE) using HLB sorbent and dissolved in the mobile phase. Next, the sample preparations were analyzed with a Reversed Phase High-Performance Liquid Chromatography (RP-HPLC). The good separation was achieved on an HPLC YMC Triart C18 (150 x $4.6 \mathrm{~mm}$, ID S-5 $\mu \mathrm{m} 12 \mathrm{~nm})$ column. The $0.1 \mathrm{M}$ buffer sodium dihydrogen phosphate mono base $\mathrm{pH} 6.00 \pm 0.05$ - methanol in the ratio 55:45 was used as the mobile phase, with flow rate of $1.0 \mathrm{~mL} / \mathrm{min}$, and column temperature was maintained at $30^{\circ} \mathrm{C}$. The eluted compound was monitored at a wavelength of $225 \mathrm{~nm}$ using an UV detector, within a run time of 23 min. Analytical procedure development yielded a good linearity at a range concentration $0.01-0.07 \mathrm{mg} / \mathrm{mL}$ with its calibration curve: $y=58985.35 x+13.88$ and the correlation coefficient of $r=0.9995$. The limit of detection (LOD) was determined as $0.0025 \mathrm{mg} / \mathrm{mL}$, meanwhile the limit of quantitation (LOQ) was 0.0075 $\mathrm{mg} / \mathrm{mL}$. The $\%$ RSD the inter-day precision was obtained $0.90 \%, 1.40 \%$ and $0.86 \%$, while the $\%$ RSD the intraday precision was obtained $1.23 \%$. The mean recovery of glipizide placebo spike was $100.68 \%$. It was concluded that the procedure is valid and can be applied for determination content uniformity of glipizide in the ER tablet dosage forms.
\end{abstract}

\section{INTRODUCTION}

Diabetes mellitus is one of the degenerative diseases and is one of the relatively high prevalence of disease in Indonesia. Sulfonylureas drug class is most common used as the treatment. Glipizide is a second-generation sulfonylurea class action mechanism to block potassium channels in the $\beta$-cells of Langerhans (Kobylinska et al., 2000) Glipizide was found in the market either in tablet immediate release (IR) and extendedrelease (ER) dosage form. Both have different matrices, especially the presence of hydroxypropyl methylcellulose (HMPC) which is a hydrophilic polymer. A lot of extended release preparations have been developed (Vo et al., 2016). In general, HPMC is used as a polymer that controls the rate of drug

\footnotetext{
* Corresponding Author

Email: ilma_nugrahani@fa.itb.ac.id
}

release (Huang et al., 2013; Maderuelo et al., 2011; Rowe et al., 2009). The extended release (ER) dosage form of glipizide expected levels in the blood can be maintained in a controlled manner to prevent hypoglycemia, reduce side effects and increase patient compliance (Brunton et al., 2008; Huang et al., 2013). One of the quality parameters in the drug assay is content uniformity. This is defined as the degree of uniformity of the amount of active ingredients in each unit (USP, 2011). For tablet, the doses of 5 and $10 \mathrm{mg}$ glipizide should meet pharmacopoeia/compendia requirements. Some previous experiments have been reported the methods for evaluate drug substance in an extended release preparation (Tan et al., 2016).

However, the analytical procedure for ER tablet of glipizide in a dosage form has not been reported. Physico-chemical information about the active ingredients of drugs such as pKa, solubility, polarity, and potential interactions between analytes and excipient is being important consideration during the preparation (Nickerson, 2011). 
In this research, the suitable preparation to clean up the analyte from ER's matrices by Solid Phase Extraction (SPE) was performed. This method is quite fast, less solvent, and easy to operate, then the procedure has been validated based on some references (Chan, 2004; Ahuja and Dong, 2005; ICH, 2005).

The HPLC system of this development procedure was adopted from the Indonesian Pharmacopeia (Indonesia Ministry of Health, 2015).

\section{MATERIAL AND METHODS}

\section{Phosphate buffer 0.1 M pH 6.0 preparation}

$13.8 \mathrm{~g}$ of $\mathrm{NaH}_{2} \mathrm{PO}_{4} \cdot \mathrm{H}_{2} \mathrm{O}$ was dissolved in $1000 \mathrm{~mL}$ of distilled water and its $\mathrm{pH}$ was adjusted with $2.0 \mathrm{~N} \mathrm{NaOH}$ until $\mathrm{pH}$ 6.0. This liquid was filtered and degassed.

\section{Standard solution preparation}

$100 \mathrm{mg}$ glipizide (accurately weighed) was dissolved in methanol quantitatively, transferred into a $100 \mathrm{~mL}$ measuring flask to obtain standard solutions with its concentrations $1 \mathrm{mg} / \mathrm{mL}$.

\section{Standard solution series for calibration curve preparation}

A series of volumes $(0.5 ; 1.0 ; 1.5 ; 2.0 ; 2.5 ; 3.0$ and 3.5 $\mathrm{ml})$ of glipizide standard in methanol $(1 \mathrm{mg} / \mathrm{ml})$ were filled into the $10 \mathrm{ml}$ volumetric flask which contained $4 \mathrm{ml}$ placebo. Afterwards, these solutions were added with buffer phosphate to volume.

Then in the extraction step with SPE, at loading phase, it was pipette $1 \mathrm{ml}$ until the elution phase. Next, this extract was transferred to the $5 \mathrm{ml}$ flask, and added with buffer phosphate to the final volume.

\section{Placebo solution preparation}

Placebo of glipizide ER tablet was prepared from polyethylene oxide, hydroxy propyl methyl cellulose (HPMC), magnesium stearate, sodium chloride, ethyl cellulose, polyethylene glycol, opadry white as coloring agent. All the matrix was dissolved in the phosphate buffer and then filtered. Further, the solution was stored as a placebo solution.

\section{Mobile phase preparation}

The mobile phase was a mixture of phosphate buffer $\mathrm{pH}$ 6.0: methanol in the ratio 55:45.

\section{Optimization of extraction}

Based on previous research, solvent extraction or liquidliquid extraction (LLE) was used in extraction of glipizide from serum and human plasma matrices (Venkata et al., 2011; Atif et al., 2013). The separation of eight antidiabetic drugs in human plasma assay also used SPE \& HPLC (Lakshmi and Rajesh, 2011).

\section{Optimization of placebo solvent}

To minimize the discrepancy between the simulated sample solvent and the mobile phase in HPLC system, the placebo solvent was selected as one of the mobile phases.

\section{Optimization of SPE cartridge (sorbent)}

The selection of appropriate SPE sorbent depends on the mechanism of interaction between the sorbent with the analyte. Analyte to be extracted is non-polar, so the type of SPE sorbent was used reversed-phase. There were four types of SPE sorbent in reversed phase, tC18, HLB, MAX and MCX (Wells, 2000; Anonim, 2014).

\section{RESULTS AND DISCUSSION}

Preliminary extraction study was carried out to look for the appropriate solvent and method based on the physicochemical properties of glipizide and excipients. The first, LLE (liquid-liquid extraction) with dichloromethane and water was done, but the recovery was below $80 \%$. The second preparation technique was SPE, and the recovery was above $80 \%$ with a constant repeatability. Therefore, in this experiment, SPE was chosen as the extraction method.

Optimization of placebo solvent was used methanol and phosphate buffer. Firstly, it was used methanol, and obtained a linear relationship between the level of concentration and area on the loading stage, but in the elution was not. It was possible that the organic solvent used was too large, which causes the analyte was not retained (breakthrough) in SPE sorbent. Next, the sample was dissolved in a phosphate buffer solution to reduce the solubility of glipizide. With the same steps, a linear relationship between the level of concentration and area on the elution stage was obtained as shown in Figure 1.

HLB sorbent, which made from a balanced ration of two monomers, the hydrophilic $\mathrm{N}$-vinylpirolidone and the lipophilic divinylbenzene, gave the greatest \% recovery compared to another reversed-phase sorbent. Its ability was unique to retain the both non-polar and polar compounds. Based on its chemical structure, the main functional groups of glipizide were sulfonylurea. This is a hydrophobic moiety and the substitution of R1 and R2 which is a hydrophilic moiety, so HLB sorbent selective for the analyte of glipizide.

Figure 2 shows there were no peaks with the same retention time with standard on the solvent's and placebo's chromatogram. Therefore, this analytical procedure can be concluded was specific for glipizide. Afterwards, the linearity test was performed by plotting the seven concentrations of placebo solution. These solutions were spiked with glipizide standard solution, which was compared to the instrument response.

Figure 3 shows that linear regression equation obtained was $\mathrm{y}=58985.35 \mathrm{x}+13.88$ with a correlation coefficient $\mathrm{r}^{2}=$ 0.9990 , in a range of concentration between $0.02-0.07 \mathrm{mg} / \mathrm{mL}$. Limit of detection and the limit of quantitation of this method were $0.0025 \mathrm{mg} / \mathrm{mL}$ and $0.0075 \mathrm{mg} / \mathrm{mL}$, respectively. 


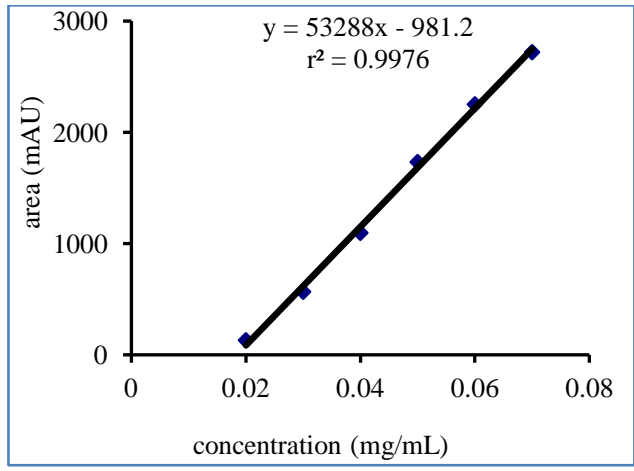

A

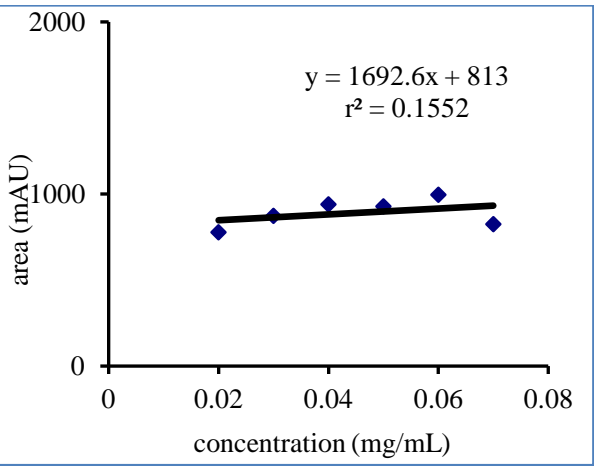

B

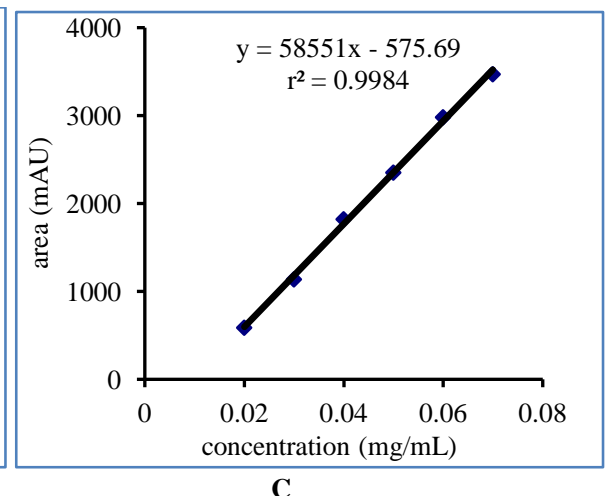

C

Fig. 1 : Calibration curve (a) the loading phase: standard solution glipizide in methanol, placebo in methanol (b) elution stage: standard solution glipizide in methanol, placebo in methanol (c) elution stage: standard solution glipizide in methanol, placebo in phosphate buffer.

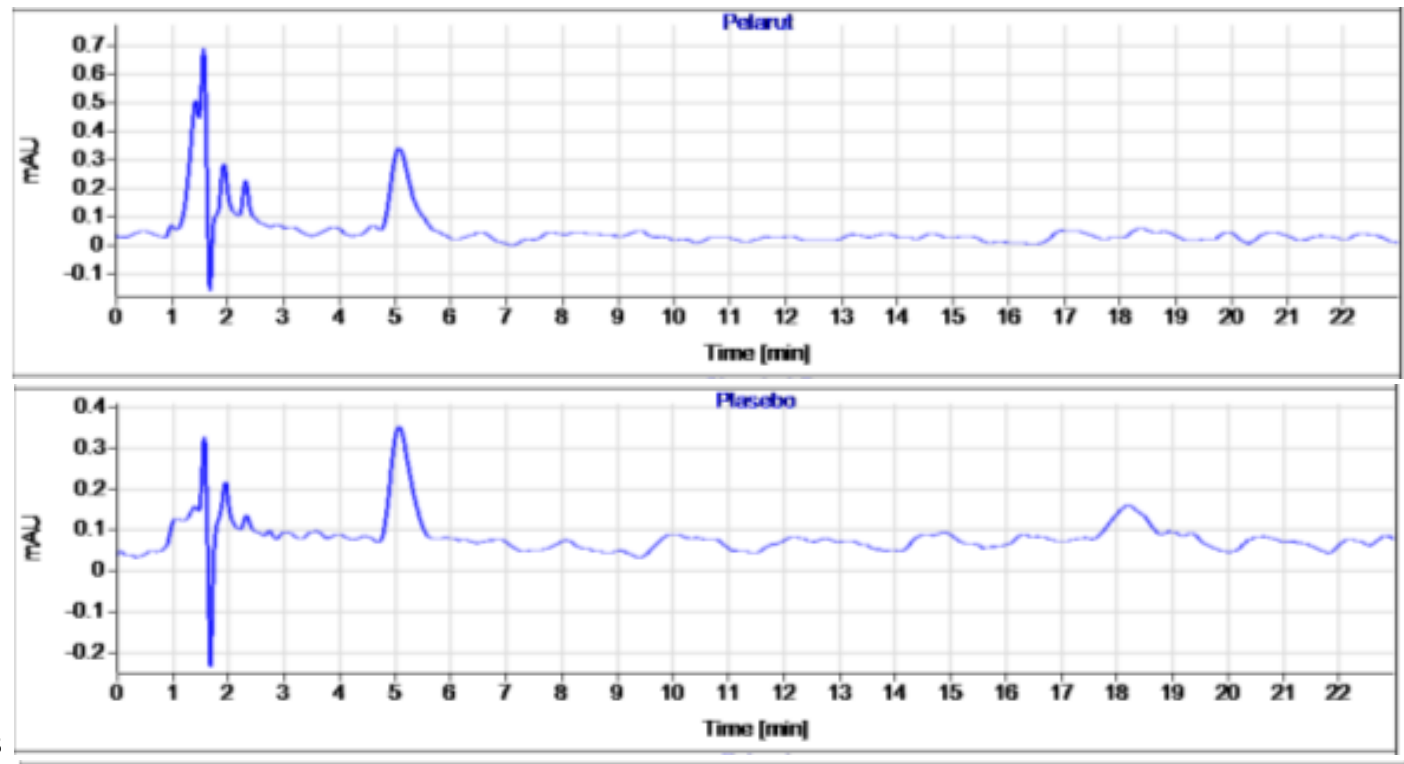

B
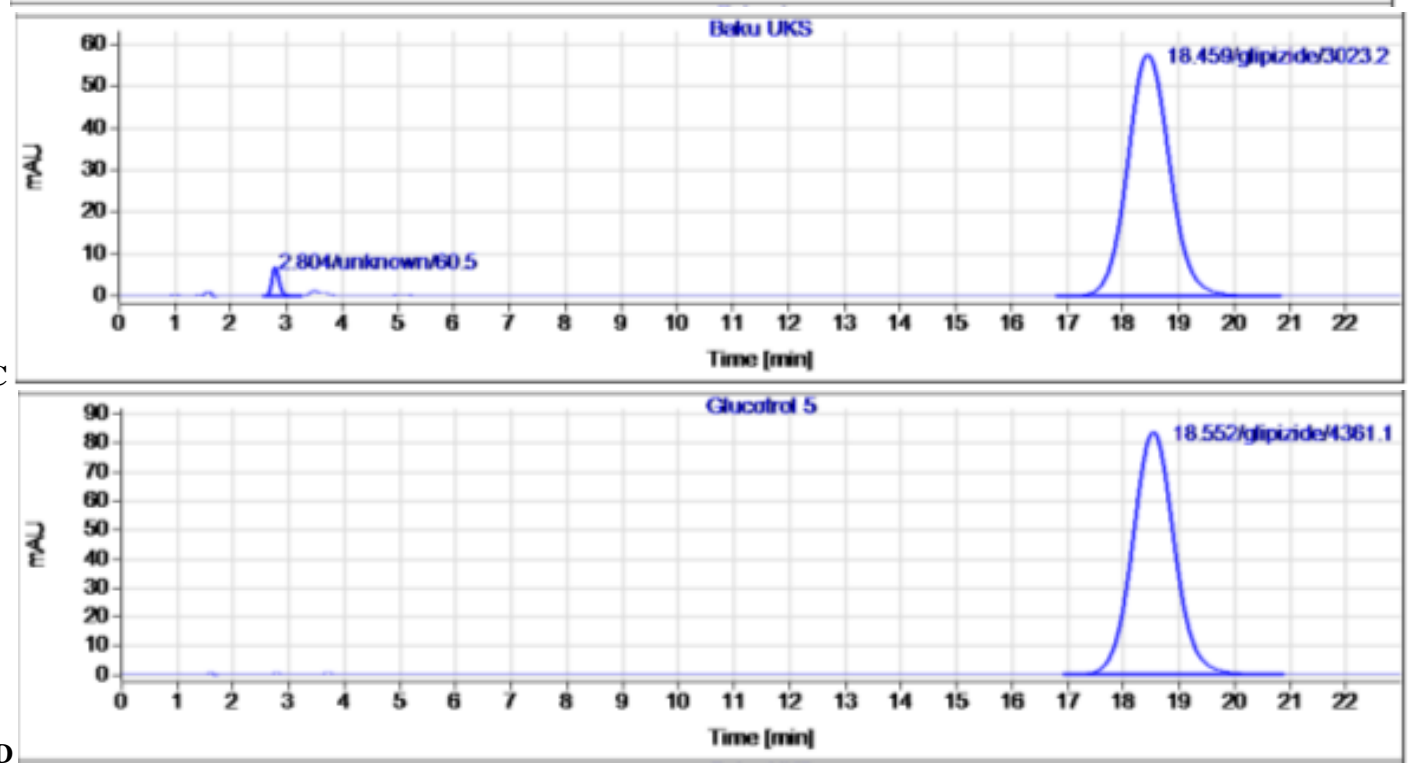

Fig. 2. Chromatogram of (a) solvent (b) placebo solution (c) glipizide standard solution (d) the placebo-spike after SPE. 


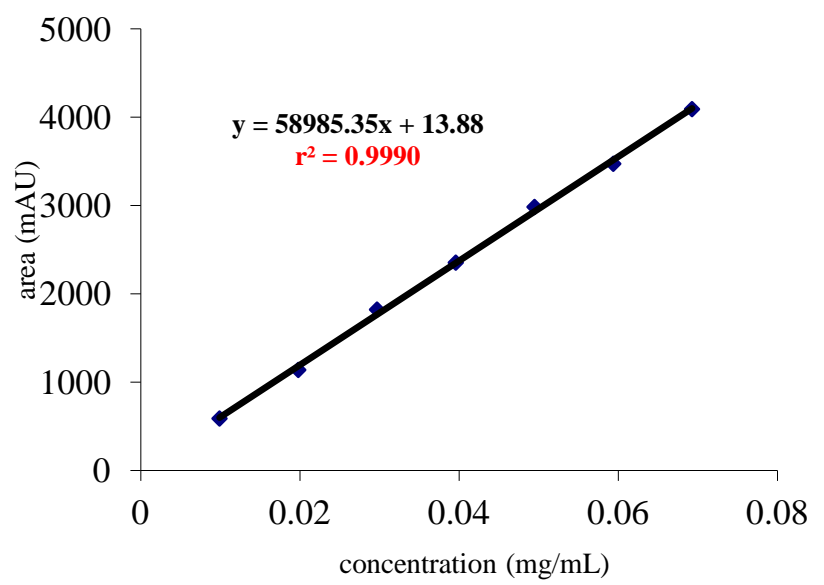

Fig. 3: Calibration curve of glipizide

Precision was performed on 6 determination at $100 \%$ and injected 3 times. The precision tests were performed intra- and inter-day for three consecutive days and the relative standard deviation not more than $2 \%$. Results of precision tests are reported in Table 1.

Table 1: Inter-day and intraday precision.

\begin{tabular}{|c|c|c|c|c|}
\hline \multirow{2}{*}{ Precision } & \multicolumn{3}{|c|}{ Interday } & \multirow{2}{*}{ Intraday } \\
\hline & 1 & 2 & 3 & \\
\hline$\% \mathrm{x}$ & 95.99 & 98.32 & 97.63 & 97.31 \\
\hline$\%$ RSD & 0.897 & 1.390 & 0.864 & 1.23 \\
\hline
\end{tabular}

Accuracy was performed by spiking placebo method at three levels, i.e., $70 \%, 100 \%$, and $130 \%$. Results of accuracy test are shown in Table 2.

Table 2: Accuracy.

\begin{tabular}{ccc}
\hline No & Label claim $(\%)$ & \% Recovery Estimated \\
\hline 1 & 70 & 98.00 \\
2 & 100 & 102.35 \\
3 & 130 & 101.82 \\
\hline
\end{tabular}

In content uniformity test, one glipizide ER tablet was transferred into a volumetric flask, then dissolved with the mobile phase. The final concentration should be $0.05 \mathrm{mg} / \mathrm{mL}$. After that, the content of tablets was determined by HPLC with an uv detector at the wavelength $225 \mathrm{~nm}$. The acceptance value (AV) of glipizide ER $5 \mathrm{mg}$ was 15.08, meanwhile the glipizide ER $10 \mathrm{mg}$ was 21.87. Both values were above the acceptance criteria of content uniformity of tablet ER, that states it should not more than 15 .

\section{CONCLUSION}

Analytical content uniformity procedure of glipizide ER has been developed with the HPLC combined with a sample pretreatment using SPE - HLB sorbent. The HPLC system arranged as follows: the mobile phase was a mixture of $0.1 \mathrm{M}$ of monobasic phosphate buffer $\mathrm{pH} 6.00 \pm 0.05$ and methanol (55:45). The flow rate was $1.0 \mathrm{~mL} / \mathrm{min}$. The column temperature was 30 ${ }^{\circ} \mathrm{C}$, UV detector was set at the wavelength $225 \mathrm{~nm}$, and Triart YMC C18 column ( 150 x 4.6 mm, ID S-5 $\mu \mathrm{m} 12 \mathrm{~nm})$ used.
Sample was prepared by SPE using a sorbent type of HLB, which conditioned with $1 \mathrm{~mL}$ of methanol and $1 \mathrm{ml}$ of distilled water. The sample loading was $1 \mathrm{~mL}$ solution, which washed with $1 \mathrm{~mL}$ water, then eluted with $1 \mathrm{~mL}$ of methanol. The HPLC measurement system obtained a good linearity at a range concentration $0.01-0.07 \mathrm{mg} / \mathrm{mL}$, with the calibration curve of $\mathrm{y}=$ $58985.35 x+13.88$, and the correlation coefficient of $\mathrm{r}^{2}=0.9990$ Limit of detection and the limit of quantitation of this method, were $0.0025 \mathrm{mg} / \mathrm{mL}$ and $0.0075 \mathrm{mg} / \mathrm{mL}$ respectively, the coefficient of variance was $1.232 \%$; and accuracy value was $100.68 \%$. Based on these results, the analysis procedure suggested as a good content uniformity testing procedure for glipizide ER tablet dosage form.

\section{ACKNOWLEDGEMENTS}

Financial support and sponsorship: The authors are thankful to Indonesia National Agency of Drug and Food Control for funding this research.

Conflict of Interests: There are no conflicts of interest.

\section{REFERENCES}

Ahuja S and Dong MW. 2005. Handbook of Pharmaceutical Analysis by HPLC. New York: Elsevier Academic Press.

Anonim. 2014. Care and Use Manual, Oasis HLB Catridges and 96 Well Plate, Milford, USA : Waters Corporation.

Atif M, Khalid SH, Kit GLO, Sulaiman SAS, Asif M, and Chandersekaran. A. Development and validation of RP-HPLC-UV method for the determination of glipizide in human plasma. J Young Pharmacists 2013;5 : 26-9.

Brunton L, Parker K, Blumenthal D, dan Buxton I, Goodman \& Gilman's. 2008. Manual of pharmacology and therapeutics. USA: McGraw-Hill Companies 1039-60.

Chan C. 2004. Analytical Methode Validation and Instrument Performance Verification. Canada: John Wiley and Sons Inc Publication.

Hennion MC. Solid-phase extraction: method development, sorbents, and coupling with liquid chromatography. J Chrom A 1999; 856 3-54.

Huang H, Wu Z, Qi X, Zhang H, Chen Q, Xing J, Chen H, Rui Y. Compression-coated tablets of glipizide using hydroxypropylcellulose for zero-order release: In vitro and in vivo evaluation. Inter J Pharm 2013; 446: 211-8.

ICH. 1994. Validation of analytical procedures: text and methodology. Geneva : International Conference on Harmonization, IFPMA.

International Conference of Harmonization (ICH). Q2 Validation of Analytical Procedures: Text and methodology international conference on harmonization of technical requirements for registration of pharmaceutical for human use. Canada: ICH Harmonized Tripartite Guideline; 2005 .

Indonesia Ministry of Health, Indonesian Pharmacopoeia, Ed IV Suplemen I, 2009. Jakarta : Indonesia Ministry of Health 1425.

Kobylinska M, Bukowska-Kiliszek M, Barlinska M, Sobik B, and Kobylinska K. Bioequivalence Study of Two Brands Of Glipizide Tablets. Act Poloniae Pharma Drug Res, 2000; 57: 101- 4.

Lakshmi KS, and Rajesh T. Separation and quantification of eight antidiabetic drugs on a high-performance liquid chromatography: Its application to human plasma assay. ISRN Pharm 2011 : 1-7.

Maderuelo C, Zarzuelo A, and Lanao JM. Critical Factors In The Release Of Drug From Sustained Release Hydrophilic Matrices. J Cont Rel 2011; 154: 2-19. 
Nickerson B. 2011. Sample Preparation of Pharmaceutical Dosage Forms: Sample Preparation for Solid Oral Dosage Form, 7. New York : Springer 145-74.

Rowe and Raymond C, Sheskey PJ, Quinn, Marian E., Handbook of Pharmaceutical Excipients, Sixth edition, Pharmaceutical Press, Washington, 2009.

Tan Y, Si X, Zhong L, Feng X, Yang X, Huang M, Wu C. Development and validation of dissolution testings in acidic media for rabeprazole sodium delayed-release capsules. Drug Dev Ind Pharm 2016: $1-9$.

The United States Pharmacopeial Convention. 2011. Uniformity of Dosage Unit. The United States Pharmacopoeia, Stage 6 Harmonization.

Venkata RI, Rao AL, and Ramana MV. Development and validation of LC method for the estimation of glipizide in pharmaceutical dosage form and serum. Int J Res Pharm Chem 2011; 1(1): 50-4.

Vo AQ, Feng X, Morott JT, Pimparade MB, Tiwari RV, Zhang F, Repka MA. A novel floating controlled release drug delivery system prepared by hot-melt extrusion. Eur J Pharm Biopharm 2016; 98: 108-21.
Wells MJM. 2000. Essential Guides to Method Development in Solid-Phase Extraction. In ID Wilson ER, Adlard MC, and Poole CF, eds. Encyclopedia of Separation Science, Vol. 10, Academic Press, London: Academic Press 4636-43.

\section{How to cite this article:}

Nugrahani I, Fatmawati I, Ibrahim S. Development and Validation of Content Uniformity Analytical Procedure of Glipizide Extended Release Tablet. J App Pharm Sci, 2016; 6 (12): 192-196. 